\title{
Tracking Angina Pectoris on the Coronary Fractional Flow Reserve
}

\author{
Shusuke Fukuoka ${ }^{1}$, Ryuji Okamoto ${ }^{2}$, Takashi Tanigawa ${ }^{1}$ and Masaaki Ito $^{2}$ \\ Key words: angina pectoris, fractional flow reserve (FFR), percutaneous coronary intervention (PCI)
}

(Intern Med 55: 2311-2312, 2016)

(DOI: 10.2169/internalmedicine.55.6558)

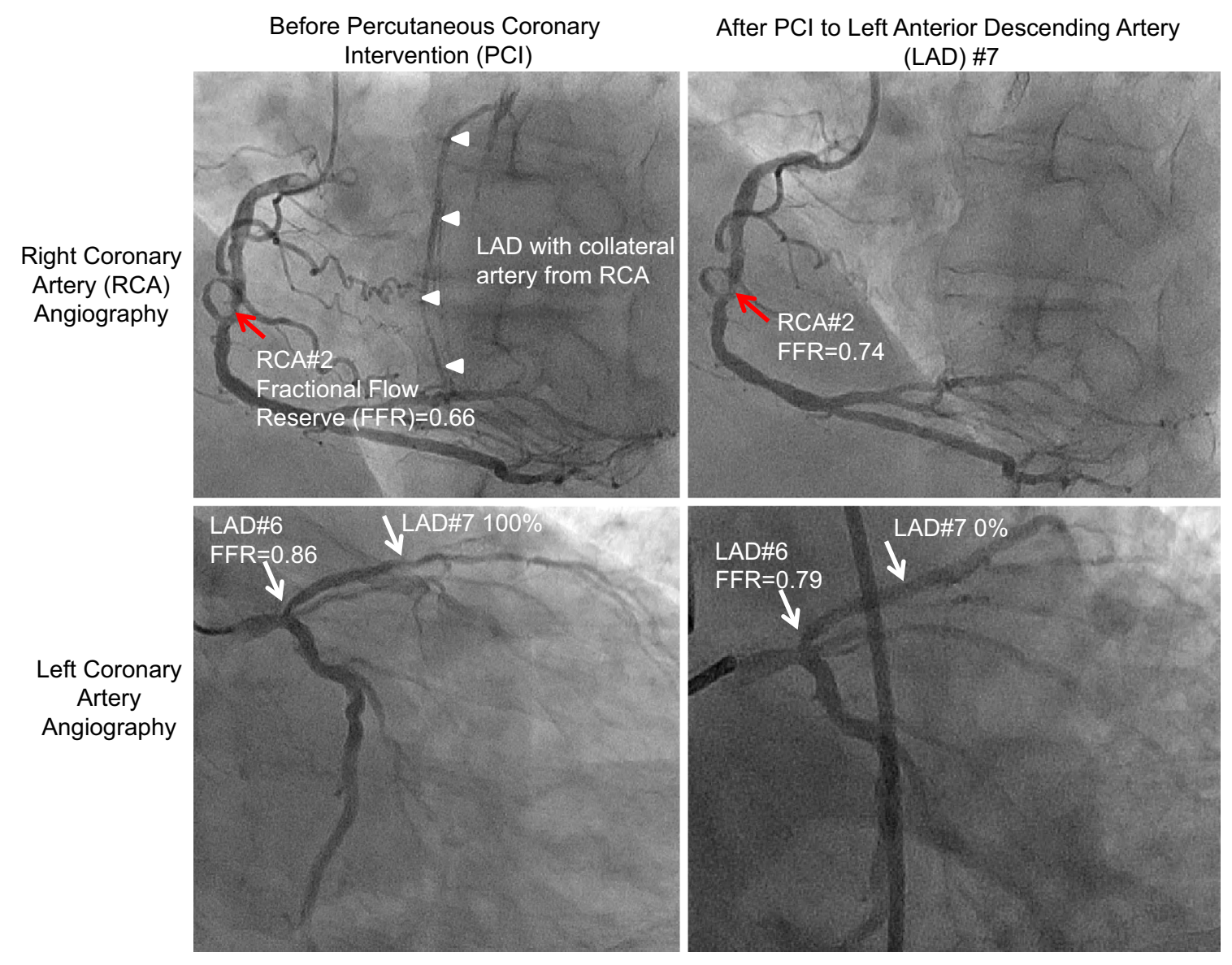

Picture.

A 75-year-old man developed effort angina and was admitted to our hospital. Angiography revealed $75 \%$ stenosis in the right coronary artery (RCA) \#2 with a fractional flow reserve (FFR) of 0.66 and $75 \%$ stenosis and total occlusion in left anterior descending artery (LAD) \#6 and \#7 with a FFR of 0.86 in LAD \#6. RCA gave rise to a collateral ar- tery to LAD (Picture). As the narrowing was not severe and it was possible to increase the FFR in RCA, we performed percutanecus coronary intervention (PCI) in LAD and assessed the change to the FFR. Interestingly, the FFR increased to $0.74(<0.75)$ in the RCA and decreased to 0.79 in the LAD. We therefore selected PCI and medical follow-up

${ }^{1}$ Cardiology Department, Matsusaka Central Hospital, Japan and ${ }^{2}$ Department of Cardiology and Nephrology, Mie University Graduate School of Medicine, Japan

Received for publication September 14, 2015; Accepted for publication November 24, 2015

Correspondence to Dr. Ryuji Okamoto, ryuji@clin.medic.mie-u.ac.jp 
in the RCA and LAD, respectively. The patient was discharged without any symptoms. Measuring the FFR has become the gold standard for guiding revascularization (1), which is considered warranted for a FFR $<0.75$. However, as observed in the present case, we should therefore pay close attention to the possibility that the FFR of the donor artery can be affected by the existence of a collateral artery (2).

If the FFR increases to more than 0.75 , then it would also be possible to select a medical follow-up in RCA\#2.
The authors state that they have no Conflict of Interest (COI).

\section{References}

1. De Bruyne B, Fearon WF, Pijls NH, et al. Fractional flow reserveguided PCI for stable coronary artery disease. N Engl J Med 371: 1208-1217, 2014.

2. Sachdeva R, Agrawal M, Flynn SE, Werner GS, Uretsky BF. Reversal of ischemia of donor artery myocardium after recanalization of a chronic total occlusion. Catheter Cardiovasc Interv 82: E453E458, 2013.

(C) 2016 The Japanese Society of Internal Medicine

http://www.naika.or.jp/imonline/index.html 